\title{
Desenvolvimento humano e gastos militares: as prescrições dos RDH (PNUD/ONU)
}

\section{Human development and military expenditures: the prescriptions of the RDHs (UNDP/ONU)}

Maria José de Rez̧ende - Doutora em Sociologia, pela Universidade de São Paulo (USP). Professora do Programa de Pós-Graduação em Sociologia e da Especialização em Ensino de Sociologia e Especialização em Comunicação Popular e Comunitária da Universidade Estadual de Londrina (UEL). E-mail: mjderezende@gmail.com

\begin{abstract}
Resumo
Os Relatórios Globais do Desenvolvimento Humano $(\mathrm{RDH})$, encomendados e publicados pelo PNUD/ONU desde 1990, têm demonstrado, por meio de vários dados e argumentos, que a expansão do desenvolvimento humano é, sobretudo, difícil naqueles países onde há gastos militares muito superiores aos gastos sociais de modo geral. Por meio de uma análise documental, este estudo está em busca do significado político, para o momento atual, das narrativas que visam construir diagnósticos e prognósticos acerca das impossibilidades de construção do desenvolvimento humano naquelas regiões do mundo onde as despesas militares ficam com uma parte expressiva dos recursos que poderiam ser direcionados a melhorias na renda, na educação, na saúde, no saneamento e na moradia adequada.
\end{abstract}

\section{Palavras-chave}

Desenvolvimento Humano. Pobreza. Despesas Militares. Estado.

\begin{abstract}
Global Human Development Reports (HDRs), ordered and taken over by UNDP / UN since 1990 have shown, through various data and arguments, that the expansion of human development is especially difficult in those countries where military spending is much higher than social spending in general. Through a document analysis, this study is in search of a political significance, for the present time, of the narratives that seek to build diagnoses and prognoses about human development building impossibilities in those regions of the world where military spending gets a significant part of the resources that could be directed to improvements in income, education, health, sanitation and adequate housing.
\end{abstract}

\section{Keywords}

Human Development. Poverty. Military Spending. State. 


\section{INTRODUÇÃO}

Desde suas primeiras edições, que se iniciaram em 1990, os Relatórios do Desenvolvimento Humano $(\mathrm{RDH})$ - encomendados, encampados e divulgados, anualmente, pelo Programa das Nações Unidas para o Desenvolvimento (PNUD) - têm demonstrado evidente preocupação com as formas de financiar as melhorias referentes aos rendimentos, à educação, ao acesso à saúde, à moradia, ao saneamento, entre outros investimentos sociais. O segundo relatório, o de 1991, já se dedicava quase integralmente ao tema do financiamento do desenvolvimento humano.

Esclarece-se que, desde 1990, várias equipes de técnicos, estatísticos, consultores, colaboradores externos ao PNUD, agentes governamentais, cientistas, redatores, entre outros indivíduos e grupos, são incumbidos de preparar, sob a coordenação de alguns técnicos graduados, como, por exemplo, Ul Haq ${ }^{1}$ (1963 , 1978, 1995) que coordenou a feitura dos primeiros relatórios da década de 1990, os documentos - RDH - que objetivam balizar as discussões globais e regionais sobre as possíveis mudanças sociopolíticas que poderiam ser buscadas e/ou que estão sendo postas em andamento para que o desenvolvimento seja capaz de alcançar as pessoas mais pobres do planeta.

Desde o RDH de 1991, o segundo divulgado pelo PNUD, já se notava que gerar, angariar, redefinir e redirecionar recursos para melhorias sociais favorecedoras dos mais pobres era o desafio maior posto aos propósitos contidos nos RDH. Isto se evidenciava na medida em que se tocava em muitos interesses difíceis de enfrentar. Observa-se, todavia, que os formuladores dos relatórios fazem diversas propostas de redirecionamento de recursos do Estado para as áreas relacionadas ao desenvolvimento humano concebido como um processo de expansão da renda e do acesso à educação, à saúde e à moradia adequada (como água potável e saneamento básico) para os mais pobres das diversas partes do mundo.

É digno de nota o fato de que os proponentes e autores dos relatórios parecem não ver possibilidade de enfrentar a situação de concentração da renda e do poder no mundo hoje, a qual tem implodido, dia após dia, a expansão do

\footnotetext{
Economista paquistanês, que, junto com o Sen (1981, 1984, 1999, 2001, 2008, 2010, 2011)), economista indiano, foi o idealizador, criador e coordenador dos primeiros RDH. Esses primeiros relatórios são considerados fonte de inspiração para todos os demais que se seguiram. Sobre isto ver o depoimento de Klalid Malik, diretor do Gabinete dos Relatórios do Desenvolvimento Humano (MALIK apud PNUD, 2013, p. 9).
} 
desenvolvimento humano. Diante de barreiras que parecem irremovíveis, pelo gritante desequilíbrio de poder em vigor no mundo atual, eles parecem mais propensos a defender propostas e ações pontuais de melhorias nas esferas econômicas, sociais e políticas. Entre as muitas sugestões de ajustamentos nos orçamentos públicos e na aplicação dos recursos, os elaboradores dos RDH insistem que os diversos países (desenvolvidos, em desenvolvimento e menos desenvolvidos $)^{2}$ enfrentam, no âmbito interno e externo, a necessidade de reduzir os gastos militares. Estes são tidos como empecilhos significativos ao desenvolvimento humano, já que afetam os orçamentos públicos de tal maneira, em vários lugares, que acabam sendo um fator impeditivo dos avanços rumo a uma política sustentável e duradoura nas diversas áreas sociais.

O objeto deste estudo são as ações e as práticas, sugeridas pelos elaboradores dos RDH da década de 1990, voltadas para a diminuição dos gastos militares, uma vez que não são, tais gastos, condizentes com a situação dos países pobres que mais necessitam de ampliar seus recursos para alcançar o desenvolvimento humano. As despesas militares dos países ricos também afetam, segundo os formuladores dos RDH, a situação das nações pobres, pois estas carecem de ajuda e aportes financeiros que podem ser exíguos em razão das decisões de investir mais em armas do que em gente. Os gastos militares são reveladores das condições globais em que se investe demasiadamente em armamentos e indústrias bélicas, e muito pouco naquelas áreas que poderiam ampliar as melhorias sociais. Tal situação pode obstar, e/ou até mesmo suprimir, qualquer expectativa de avanços expressivos em relação ao desenvolvimento humano.

Em vista deste objeto, levantam-se os seguintes problemas sociológicos: de que recursos argumentativos as equipes produtoras dos RDH lançam mão para sugerir processos contínuos de diminuição dos gastos militares ${ }^{3}$ que subtraem ao desenvolvimento humano suas chances de ampliação? Partindo do pressuposto de que os argumentos tecidos nos RDH não são autônomos, mas sim parte de um dado contexto sócio-histórico, de um entrançado de jogos configuracionais e de múltiplas relações de interdependências, pretende-se compreender como os $\mathrm{RDH}$ propõem sugestões para a diminuição das despesas militares exacebadoras,

\footnotetext{
Essas caracterizações são feitas pelos próprios produtores dos $\mathrm{RDH}$.

Os elaboradores do RDH de 1991 definem gastos militares da seguinte maneira: "Gastos militares. Los gastos efectuados, ya sea por el Ministerio de Defensa u otras dependencias, en el mantenimiento de las fuerzas militares, incluyendo adquisición de provisiones y equipos militares, construcción, reclutamiento, entrenamiento y programas de asistencia militar" (PNUD, 1991, p. 262, grifos do autor).
} 
em vários países, de práticas belicosas e conflituosas que minam toda e qualquer possibilidade de desenvolvimento humano e sustentável.

Considera-se essencial, ainda, buscar responder aos seguintes problemas postos a esta pesquisa: entre os muitos problemas políticos que devem ser enfrentados, internamente, por diversos países, de que forma os elaboradores dos RDH elegem a expansão das despesas militares como uma fonte do agravamento das dificuldades que fragilizam economicamente os Estados e subtraem as possibilidades de fazer avançar o desenvolvimento humano? Quais são as nações e regiões (continentes) mais oneradas por despesas militares desproporcionais às demais despesas prioritárias ao desenvolvimento humano?

Se este artigo está voltado, essencialmente, para as sugestões dos RDH da década de 1990 de diminuição dos gastos militares, como forma de construir um fundo maior de recursos para aplicação nas políticas de desenvolvimento humano (ou seja, políticas de saúde, educação, saneamento, moradia adequada, nutrição de crianças, entre outras), isto não quer dizer que os relatórios se atêm somente a este tipo de gasto e suas consequências para as políticas de melhorias sociais.

No entanto, a constituição deste fundo passa, não só pela redução das despesas militares, mas também pela reestruturação das políticas orçamentárias nacionais de modo geral. Passa ainda, como consta no RDH de 1991, pelo combate à fuga de capitais e à corrupção. Outras duas ações tidas como relevantes seriam: 1- o acirramento de pressões dos organismos internacionais, que operam com empréstimos, cooperação e doações, sobre os governos dos diversos países (tal pressão deveria estar voltada para que os governantes não utilizem parte expressiva dos recursos internos e externos em atividades belicosas); 2- a diminuição dos encargos referentes à dívida externa que tem onerado demasiadamente os países latino-americanos ${ }^{4}$, que, por exemplo, na década de 1990 "utilizaron cerca del $24 \%$ de los ingresos por exportación para asegurar el servicio de la deuda (aun así, esta suma no cubrió todos los intereses adeudados)" (PNUD, 1991, p. 110).

Os encampadores e autores dos RDH sugerem ações externas coordenadas para evitar que os governantes direcionem grande fatia dos recursos a áreas militares.

Los actores externos del desarrollo pueden plantear problemas políticos profundos, tales como los que rodean la reforma agraria o los gastos militares. [...] Si los donantes ejercieran presión para que se adoptara este tipo de

\footnotetext{
Ainda mais grave é a situação de alguns outros continentes, pois "la deuda total de los países africanos de bajos ingresos es cinco veces su ingreso anual por exportaciones. En 10 de estos países, la deuda es 10 veces superior al ingreso, y el servicio de la deuda representa en promedio el 80\% de sus exportaciones" (PNUD, 1991, p. 110).
} 
reforma, probablemente descubrirían a mucho aliados en los países en desarrollo y lograrían cambios muchos más grandes que los mejoramientos marginales con los cuales suelen contentarse (PNUD, 1991, p. 33).

\section{OS GASTOS MILITARES E O IMPACTO SOBRE AS POLÍTICAS COMPROMETEDORAS DO DESENVOLVIMENTO HUMANO}

Nas décadas de 1940 e 1950, Josué de Castro, presidente da FAO (Organização das Nações Unidas para Agricultura e Alimentação) ${ }^{5}$ entre 1952 e 1956, já colocava uma pergunta que de alguma forma aparece novamente nos RDH: o que é mais importante para a humanidade, o pão ou o aço? O livro Geografia da fome (CASTRO, 2001), cuja primeira edição é de 1948, partia do pressuposto de que o problema principal do Brasil e do mundo ${ }^{6}$, naquele momento, era a corrida armamentista, a militarização, o empenho para expandir a indústria bélica e a exportação de armas, bem como o descaso que vigorava, entre os governantes e os setores mais abastados, em relação à pobreza, à fome e à miséria que assolava uma parte expressiva da humanidade.

A indagação de Josué de Castro (pão ou aço?) veio à tona, nos anos subsequentes, nos estudos sobre a distribuição dos gastos e recursos públicos, pela expressão "manteiga vérsus canhões" (DIKICI, 2015). "O conceito de trade-off em defesa é tradicionalmente conhecido como o dilema 'manteiga versus canhões', ou 'arados versus espadas'. Segundo este ponto de vista, a nação deverá alocar seus recursos de forma a produzir bens 'civis' ou 'militares', de acordo com sua necessidade" (ALMEIDA, 2013, p. 431).

Os elaboradores dos $\mathrm{RDH}$ fazem seus diagnósticos e prognósticos, referentes aos processos de contabilização dos gastos sociais e militares, balizados pela forma de distribuição de recursos que tem desfavorecido o desenvolvimento humano.

A noção do trade-off opera uma sensível mudança no próprio conceito de custo. [...]. Neste caso, o custo envolvido na tomada de decisão deixa de ser avaliado em termos puramente financeiros para incorporar a ideia de que o custo de se produzir algo corresponde à opção de deixar de produzir alguma outra coisa também necessária. O custo de um avião de combate, ou de uma nova unidade naval, deixa de ser medido apenas em milhões de dólares para ser medido, também, em termos daquilo que deixa de ser oferecido à nação, por exemplo, ensino fundamental ou saúde básica (ALMEIDA, 2013, p. 431).

A FAO é uma agência especializada das Nações Unidas.

O livro intitulado Geopolitica da fome (CASTRO, 1961) mostrava que a fome estava presente nos vários continentes. 
Deve-se ressaltar que a correlação entre os crescentes gastos militares e as dificuldades de ampliação de melhorias sociais e dos investimentos em seguridade social não é algo que estreia nos RDH. Esta é uma discussão que tendeu a ganhar força nos períodos de crises econômicas, de retração dos gastos sociais, de tentativas de ampliar a seguridade social e de recuperação econômica nas décadas após as guerras que acabaram por tornar os gastos militares exorbitantes. É inteiramente previsível que, no momento atual, as prescrições para alcançar o desenvolvimento retomem estas propostas de diminuição dos gastos militares. “Em 2009, as despesas militares globais aproximaram-se dos 3\% do PIB mundial, enquanto alguns países gastaram muito mais, incluindo os Estados Unidos (4,7\% do PIB) e a Federação Russa (4,3\% do PIB)" (PNUD, 2011, p. 97).

Após a Segunda Guerra Mundial, este debate tomou fôlego em várias frentes. Economistas, sociólogos, organismos internacionais e organizações não governamentais - a SUPRI (Instituto Internacional de Estudos para a Paz Estocolmo) pode ser citada como exemplo - entram neste debate com o intuito de ressaltar a necessidade de tornar público que as despesas militares crescentes eram fatores que ampliavam as dificuldades de resolver os candentes problemas sociais, uma vez que, conforme alertava W. Mills, nos Estados Unidos, "dois em cada três dólares do orçamento anunciado em 1955 destinavam-se à segurança militar" (MILLS, 1981, p. 254).

Sweezy e Baran (1966) entraram nesta seara com o livro Monopoly Capital - an essay on the American economic and social order. Deduzem em suas reflexões sobre a situação americana no pós-guerra e os meandros do capitalismo monopolista como um todo, que os investimentos sociais, nos momentos de crises econômicas e sociais agudas, são tímidos enquanto que os gastos militares tendem a ser crescentes, visto que a "indústria de armamento funcionando como absorvente de mais-valia e reduzindo o problema do desemprego é um corolário do crescimento econômico no capitalismo monopolista" (CARILHO, 1978). Em resposta a essas considerações, Szymanski (1973), no artigo intitulado Military spending and economic stagnation, fundamentado em sua pesquisa - que recolheu dados em 18 países avançados - diz que "o hiperdesenvolvimento da indústria de armamento não seria necessário ao capitalismo monopolista" (CARILHO, 1978, p. 166).

Assinale-se que, além deste debate econômico acerca da indústria bélica, na segunda metade do século XX, estão envolvidas ainda muitas outras coisas

Sobre o contexto norte-americano no qual floresce este debate, ver Custers (2009).

S Sweezy (1973) contesta com veemência esta tese. 
quando se tem em pauta a diminuição das despesas militares. Dela deriva um enfrentamento político de grande monta, mesmo que haja um razoável equilíbrio de poder entre militares e civis (HARTLEY; SANDLER, 1995, 2007; DEGER; SEN, 1995). Em condições autoritárias, em que há um desequilíbrio de poder em favor daqueles primeiros, fica quase impossível pautar propostas de revisões dos recursos destinados às instituições militares.

Todavia, em qualquer situação, quando é mencionada a necessidade de redução de tais gastos, parte de militares e de seus apoiadores, insistem que o propósito disso é de natureza política e que isso geraria "intranquilidade na instituição militar, uma vez que este decréscimo de recursos pode ocasionar uma intensificação do controle civil sobre os militares e paralelamente tornar a tarefa de adaptação à nova conjuntura mundial mais difícil” (BALTAZAR, 2000, p. 4).

Baltazar (2000), em um paper apresentado no IV Congresso Português de Sociologia, em abril de 2000, insiste que a conjuntura internacional, no limiar do século XXI, exige a ampliação das missões militares e, ao mesmo tempo, há um apelo para que haja o "decréscimo do volume de despesas militares e de pessoal na instituição militar" (BALTAZAR, 2000, p. 13). A pesquisadora da Universidade de Évora atesta, em seu texto, que tem havido redução das despesas militares. Ainda que ela não deixe isto muito claro, pressupõe-se que ela esteja falando de Portugal. Há em sua análise uma visão favorável aos militares, pois ela ressalta que eles desempenham, no contexto internacional, hoje, muitas tarefas e possuem muitas responsabilidades e missões que devem ser consideradas quando se busca colocar o tema do decréscimo das despesas militares em questão. A diminuição das despesas militares é, sem dúvida, uma tarefa dificílima, pois "em todo o mundo, as despesas militares ultrapassaram 1,4 bilhões de dólares em 2010, mais do que o PIB combinado dos 50 países mais pobres do mundo" (PNUD, 2013, p. 22). Conforme demonstra Elias (1991), os desequilíbrios de poderes, no âmbito mundial, são visíveis nos aparatos bélicos e na força militar dos países que os possuem ou daqueles que os não possuem. As muitas assimetrias, entre os países, são notórias pelo modo como eles podem, ou não, se impor na ordem global.

São visões ancoradas na ideia de que há uma ampliação dos conflitos e isto exige maior vigilância e maior controle. Os militares estariam incumbidos de tais tarefas. Os elaboradores dos PNUD (1991, 1992, 1994, 1995, 1996, 1998, 1999) consideram que, se os países cumprissem suas tarefas no campo da expansão de políticas favorecedoras do desenvolvimento humano, seriam cada 
vez menores as necessidades policialescas. "En muchos países, las disparidades socioeconómicas, la delincuencia, las presiones políticas y la necesidad de una vigilancia policiva podrían reducirse si se prestara más atención al desarrollo humano" (PNUD, 1991, p. 24).

Diferentemente do que está posto nesta citação do RDH de 1991, grosso modo, o general brasileiro Augusto Heleno Pereira, em 16 de novembro de 2015, em artigo publicado no jornal Folha de S. Paulo (PEREIRA, 2015), reitera a posição de Baltazar (2000). Segundo ele, “os militares cumprem qualquer missão, além de suas tarefas constitucionais. Ainda assim, são mal remunerados e dispõem de orçamento destroçado" (PEREIRA, 2015, p. 3).

Dá para se ter uma ideia das resistências que se têm manifestado e devem ainda se manifestar ao longo do século XXI, em várias partes do mundo, em relação a estas propostas dos $\mathrm{RDH}$ de redução das despesas militares. E ainda que haja alardes de que existe uma diminuição dos orçamentos militares, principalmente por parte daqueles que saem em defesa das forças armadas e de suas tarefas exorbitantes na gestão de crises e conflitos exacerbados no contexto atual $^{9}$, é visível, segundo alguns estudos (como os da SIPRI), que, no limiar do século XXI, os gastos militares diminuíram muito pouco. No mundo, nos anos de 2012 e 2013, a SIPRI constatou que houve um recuo de 1,9\% das despesas militares. O Brasil ${ }^{10}$, por exemplo, neste mesmo período teria tido uma diminuição de 3,9\% dos gastos militares ${ }^{11}$. Assim, o país perdeu sua posição entre os 10 que mais gastam em $\operatorname{armas}^{12}$ (SIPRI, 2015).

O RDH de 2013 (p. 41-2), ao buscar diferenciar a situação dos diversos países, faz a seguinte afirmação: “Entre 1990 e 2010, as despesas militares mais do que triplicaram nos países com IDH médio, aumentando quase 50\% em países com IDH baixo e $22 \%$ em países com IDH muito elevado, e diminuindo praticamente 47\% em países de IDH elevado" (PNUD, 2013, p. 41-42).

\footnotetext{
$9 \quad$ Em 27 de dezembro de 2015, no Jornal de Negócios de Portugal, Schauble (2015), o ministro das finanças da Alemanha, afirmou que a crise dos refugiados exige uma ampliação das despesas militares alemãs e que espera a criação de um exército europeu comum.

10 O país estava, em 2013, em 12o lugar em gastos militares no mundo. Sobre isto ver: Brasil (2014). Brustolin (2009) demonstrou que há uma grande dificuldade, no Brasil, para controlar as despesas militares. O RDH de 1994 (PNUD, 1994, p. 66) afirma que tanto as dívidas militares quanto todos os gastos das indústrias bélicas estão rodeados de muros intransponíveis. Sobre os gastos militares no Brasil entre 1991 e 2009, ver Silva Filho e Moraes (2012).

11 Sobre a América Latina, o RDH de 1991 (PNUD, 1991, p. 86) diz: "la región no gasta mucho en aspectos militares: la proporción de gastos militares a gastos en salud y educación es inferior a una tercer parte el promedio del mundo en desarrollo".

12 Sobre estes e outros dados sobre as despesas militares no mundo hoje, ver Brasil (2014).
} 
O Relatório anual de 2003 da Comissão das Comunidades Europeias, seção de Serviço de Ajuda Humanitária da Comunidade Europeia (ECHO) ressaltava algo que estará muito presente no seio dos RDH das décadas de 1990 e 2000: o que os países ricos destinam para a ajuda humanitária é uma quantidade ínfima se comparada com o que eles gastam em despesas militares. No relatório de 2002 consta que as despesas militares haviam chegado a 839 bilhões de dólares. $\mathrm{O}$ documento atestava que de um lado estavam as cifras astronômicas voltadas a atividades belicosas e de outro a ampliação global das carências e miserabilidades (RELATÓRIO DA COMISSÃO ECHO, 2003).

Os elaboradores dos RDH, com o intento de falar aos Estados nacionais e às organizações da sociedade civil acerca da necessidade de criar fundos internos e externos para financiar o desenvolvimento humano, afirmavam que este último tornava-se irrealizável, caso persistissem, em várias partes do mundo, por parte dos que detêm poder de mando e decisão, uma cooperação despreocupada tanto com o caráter militarista e belicoso dos países que recebem ajuda quanto com uma política de cooperação internacional e de ajuda financeira movida por fins estratégicos de domínio, pelas armas, de países e regiões inteiras. Ao se pautar esta discussão, não se deve esquecer também da "crescente presença das corporações multinacionais no seio do complexo militar-industrial" (HERRERA, 2006, p. 1).

Constam, nos RDH, críticas ao modo como, em diversas regiões do mundo, os recursos públicos são canalizados para atividades belicosas. Em vários países, parte dos recursos é destinada para gastos militares, os quais são "efectuados, ya sea por el Ministerio de Defensa u otras dependencias, en el mantenimiento de las fuerzas militares, incluyendo adquisición de provisiones y equipos militares, construcción, reclutamiento, entrenamiento y programas de asistencia militar" (PNUD, 1991, p. 262).

Os elaboradores do RDH de 1991 demonstram que há países assolados por fome, pobreza, analfabetismo e precariedades sociais de toda natureza aos quais se remetem ajudas internacionais que são, muitas vezes, canalizadas para ações belicosas tendentes a agravar, continuamente, a situação das populações que dependem da implantação de melhorias sociais contínuas e duradouras. Em muitas situações fica evidente que a proporção de recursos destinados às áreas militares é muito maior do que o montante destinado às áreas sociais. É muito maior porque não se tem conseguido formar dividendos e fundos em favor da paz, mas sim em prol da guerra. 
Não há dúvida que são muitos os custos adicionais para que as políticas de desenvolvimento social e humano se tornem realidade. No mundo hoje seria, segundo consta no RDH de 1991, impossível suprir estes custos sem reduzir os gastos militares. Tal redução tem de ser feita não só nos países pobres, mas também nos demais:

Si los países industriales redujeran sus gastos militares en un 3\% anual, esto significaría US $\$ 25.000$ millones al año. Y si los países en desarrollo simplemente congelan sus gastos en los niveles actuales, esto ahorraría incrementos futuros potenciales superiores a los US $\$ 10.000$ millones anuales (PNUD, 1991, p. 35).

Ao comparar as despesas militares com as despesas sociais, quais são os indicadores, apontados nos $\mathrm{RDH}$, passíveis de revelar que os gastos sociais recebem muito menos aporte do que seria necessário? A esperança de vida ao nascer, o acesso, ou não, à saúde, à água potável, ao saneamento, à moradia adequada, a um consumo calórico diário suficiente e à alfabetização são capazes de revelar o grau e as condições de privação dos grupos mais empobrecidos. Os indicadores sociais são compostos ainda pelo número, entre os mais pobres, de pessoas matriculadas no ensino básico, pelas taxas de evasão escolar, pelo índice de mortalidade de crianças e de mães ao dar à luz, pelo grau de nutrição e/ou desnutrição de crianças e adultos e pelo número de indivíduos das zonas urbanas e rurais que vivem abaixo da linha da pobreza ${ }^{13}$. Estes indicadores têm de ser situados numa condição em que "los 1.000 millones de personas más ricas tienen ingresos 60 veces superiores a los 1.000 millones de personas más pobres" (PNUD, 1994, p. 2). O RDH de 2002 ao tratar das desigualdades no mundo no limiar do século XXI afirma que "o rendimento dos 5\% mais ricos do mundo é 114 vezes o dos 5\% mais pobres" (PNUD, 2002, p. 19).

Os RDH trazem dados que demonstram haver, em vários países, disparidades gritantes tanto entre o que é gasto na área social e o que é gasto na área militar, quanto entre a renda dos mais ricos e a dos mais pobres no mundo atual. Os elaboradores dos relatórios fazem, então, muitos diagnósticos acerca da carência de recursos na área social, e como tal carência afeta o processo de desenvolvimento humano. Como há sempre uma tendência geral dos dirigentes e governantes em justificar que não se empregam mais recursos na área social

13 "Linea de pobreza. El nivel de ingresos por debajo del cual no es posible, desde el punto de vista económico, garantizar una dieta mínimamente adecuada en términos nutricionales, así como requerimientos no alimenticios esenciales" (PNUD, 1991, p. 263 grifos do autor. 
porque tais recursos não existem, os produtos dos RDH procuram demonstrar que é necessário, antes de tudo, discutir onde os recursos públicos são alocados. Ao buscar os dados sobre as despesas públicas, eles detectam que em muitos países, extremamente pobres em aplicação de verbas na área social, há gastos suntuosos nas áreas militares.

Não há verbas para a educação, saúde, saneamento e moradia, mas há recursos, insistem os autores do RDH de 1991, para investir em atividades belicosas de modo geral. Consta, no RDH de 1991, a seguinte passagem:

Cerca de US $\$ 50.000$ millones anuales un 2\% del PNB de los países en desarrollo podrían asignarse a propósitos más productivos. [...] En algunos de los países más pobres, se gasta el doble en asuntos militares que en salud y educación, como es el caso de Angola, Chad, Pakistán, Perú, Siria, Uganda y Zaire (PNUD, 1991, p. 24).

$\mathrm{Na}$ discussão sobre como financiar o desenvolvimento humano, os elaboradores do RDH de 1991 insistem que não se deve supor que os exorbitantes gastos militares são postos em prática somente nos países que compõem o quadro dos que são considerados potências mundiais (tais como: Estados Unidos, China, França, Alemanha e Rússia). Também os países extremamente pobres direcionam uma parte expressiva de seus recursos para a área militar. E este direcionamento se dá às custas da inseguridade humana absoluta, em razão de que os níveis de investimentos na área social são geralmente baixíssimos. Por isso, no prefácio do RDH de 1991, William H. Draper, administrador do PNUD, faz a seguinte observação:

Al examinar la disponibilidad de recursos financieros para la puesta en práctica de los objetivos humanos, el Informe llega a una conclusión radical: por lo general, la verdadera causa del abandono en que se encuentra el hombre está en la ausencia de compromiso político, más que en la escasez de recursos financieros (DRAPER apud PNUD, 1991, p. 14).

Assim como todos os RDH, o de 1991 divide-se em duas grandes partes: a dos diagnósticos e a das prescrições. Como este documento versa sobre o financiamento do desenvolvimento humano, sua narrativa caminha, ininterruptamente, da constatação das causas do baixo investimento em áreas atinentes ao desenvolvimento humano ${ }^{14}$ - concebido como a geração de melhorias

14 A noção de desenvolvimento humano, na década de 1990, estava ancorada, basicamente, em três eixos: renda, saúde e educação. Estes eixos foram ampliados na primeira década do século XXI, quando eixos como moradia adequada (saneamento, sustentabilidade ambiental, água potável), democratização, participação política e governança ganham mais e mais terreno. Não 
contínuas nas áreas da renda, da saúde, da educação, do saneamento e da moradia adequada - para as prescrições. Nota-se que os diagnósticos são mais robustos que as prescrições, uma vez que estas tendem a desencadear enfrentamentos políticos de grande monta.

Não há dúvida de que, se há dificuldades no processo de construção das prescrições de modo geral, tais dificuldades ficam evidenciadas no que tange ao enfrentamento das desigualdades, da concentração de riqueza e poder. Desse modo, é claro que tais fragilidades vão aparecer, com insistência, quando se tratar do financiamento das políticas que levam ao desenvolvimento humano. Isto decorre do fato de que há, por parte dos elaboradores dos $\mathrm{RDH}$, uma série de cuidados, já que se está a sugerir redimensionamentos de gastos que são de alçada exclusiva dos Estados nacionais. Mas ainda assim, mesmo que os RDH não tomem a pobreza e as desigualdades "como um fato dado e imodificável" (ETCHICHURY, 2015, p. 58) nos moldes do relatório do Banco Mundial intitulado World Development Report de 2015, verifica-se também que os RDH têm uma grande dificuldade de enfrentar, não só nos diagnósticos, mas também nas prescrições, os elementos que têm potencializado enormemente as desigualdades hoje.

Não há como desconsiderar o emaranhado de interesses internos de cada país ao sugerir ações em prol de um investimento mais comprometido com o desenvolvimento humano. Diante de tal situação, talvez, uma das tarefas mais difíceis seja a tentativa de reduzir os gastos militares. Se é difícil controlar os demais gastos do Estado, na maioria dos países, imagine-se, quão mais difícil é controlar os atinentes às áreas militares. Se a transparência dos gastos públicos é um gigantesco desafio nos países da América Latina, da África, da Ásia e da Oceania, imaginem-se as implicações de sugerir a diminuição das despesas militares, área em que é muito difícil um controle externo efetivo.

A instabilidade política vigente no final do século XX e no limiar do XXI é mostrada, por parte dos produtores dos RDH, como impulsionadora dos gastos militares tanto por parte dos países ricos quanto por parte dos países do terceiro mundo ${ }^{15}$. O desenvolvimento humano estaria sendo prejudicado nas regiões mais pobres pelas fortes turbulências que ganhavam terreno em alguns

são eixos novos, mas sim desdobramento daqueles primeiros. Ver: Sen (1999, 2008, 2010, 2011) e Ul Haq $(1978,1995)$.

15 Ressalte-se que no RDH de 1991 (PNUD, 1991, p. 190) aparece esta expressão. Muitas vezes, notam-se algumas estratégias narrativas destes documentos para evitar este termo. Mas nos primeiros relatórios, os quais tinham uma influência muito grande de seu idealizador, Mahbud Ul Haq, esta expressão aparecia. Ul Haq (1978) utilizava esta expressão no subtítulo de um de seus livros mais famosos: A cortina da pobrez̨a: opcões para o terceiro mundo. 
lugares do mundo. No Golfo Pérsico, por exemplo, onde os gastos militares chegavam, dizem os produtores do RDH de 1991, a 13\% do PIB, tinha-se uma situação de grande prejuízo ao desenvolvimento humano, uma vez que o gasto militar era "equivalente a casi al doble de los gastos en salud y educación" (PNUD, 1991, p. 88).

As zonas de conflito potencializam gastos militares de outras regiões do mundo que geralmente interferem nelas. É o caso dos EUA, da Europa e da Rússia. Por essa razão, os documentos do PNUD insistem que a possibilidade de o desenvolvimento humano se tornar viável depende do apaziguamento dos conflitos em todas as partes do mundo. Examinando-se as prescrições dos RDH no que tange a esta situação específica de geração no mundo de uma cultura de paz, de combate a toda forma de guerra e belicosidade, observa-se que, de fato, os diagnósticos e prescrições remetem a políticas de longuíssimo prazo. Em síntese, o custo das guerras (PNUD, 1991, p. 188) detona as expectativas de alcançar, em curto prazo, melhorias contínuas e duradouras que levariam a um desenvolvimento humano que seria capaz de retirar as pessoas da pobreza extrema.

Deve-se atentar para o fato de que as prescrições contidas nos RDH e dirigidas aos Estados nacionais, referentes à diminuição dos gastos militares, estão partindo de um diagnóstico centrado nas despesas públicas com as forças $\operatorname{armada}^{16}$. Na citação acima aparece a preocupação em assinalar que há redução dos gastos militares em andamento, todavia, conforme assinala Dario Azzellini (2013), se os gastos públicos diminuíram, isto não significa que há uma desmilitarização em curso no mundo ${ }^{17}$, pois as Privates Military Companies (PMC) estão em ascensão em várias partes do planeta. Isto pode ser verificado quando se analisa a relação entre soldados regulares e não-regulares (os que prestam serviços a estas Companhias Militares Privadas (CMP). "Los últimos datos oficiales son del 2007, cuando según informaciones del mismo Ejército de EEUU en Irak había 180.000 empleados de CMP, más que soldados de EEUU y todos los demás aliados en su conjunto" (AZZELLINI, 2013, p. 247).

Evidencia-se, então, que os que produzem os RDH apressam em supor que estaria em curso um processo crescente de investimento na paz e de refutação

16 Sobre o fim da guerra fria, a necessidade de repensar as despesas militares e a constituição de uma nova reengenharia política e econômica de adaptações e ajustes das despesas militares a uma nova conjuntura mundial, ver (FERNANDES, 2006, p. 16-20).

17 "Por ejemplo, durante la primera guerra en contra de Irak [1991], una de cada cien personas presentes en el campo de batalla, pertenecía a una CMP; posteriormente en Afganistán [2001] ya era una de cada cincuenta, y en Irak al principio de la guerra [...] [2003-2011] era una de cada ocho" (AZZELLINI, 2013, p. 247). 
da guerra. Todavia, as formas de financiamento da guerra, com a privatização dos serviços militares é que estariam, em parte, sendo redefinidas. O raciocínio que aparece nos RDH é o seguinte: a diminuição dos gastos públicos com as forças armadas poderá ser revertida em favor dos gastos sociais. Claro que isto não ocorreria de modo automático, pois exigiria muita negociação, dentro dos próprios estados, para que o que foi subtraído das despesas militares migrasse para as áreas sociais.

El avanzar un poco más y llegar a un compromiso serio para invertir el dividendo de la paz lo más productivamente posible requerirá una acción mucho más positiva. Se requiere ahora un diálogo vigoroso para darle a estos ahorros potenciales un uso benéfico (PNUD, 1991, p. 189-190).

Os relatórios da década de 1990 tentam fazer crer que há, de uma forma ou de outra, ainda que de modo incipiente, por parte dos países do chamado primeiro mundo, preocupação em promover uma política voltada para a paz. Em relação a isso basta ver, por exemplo, o que o RDH de 1991 (PNUD, 1991, p. 192) traz de propostas que deveriam ser levadas a cabo por estas nações. Os elaboradores dos relatórios constroem uma dada perspectiva ideológica quando confundem um ideal de comprometimento com a paz com o que de fato existe de políticas voltadas para isto. Conforme ensina Norbert Elias (1994a, 1994b, 1998, 2001), a ideologia não é somente "uma falsificação determinada por certos interesses" (ELIAS, 2001, p. 120), mas sim a construção de sistema de ideias e valores onde o que se deseja parece confundido "com o que existe observavelmente" (ELIAS, 1994a, p. 74).

A luta pela paz parece mais incerta nos países do terceiro mundo, mas muito mais possível e viável nos países do eixo norte. Há um desejo de que os países industrializados estejam envolvidos com discursos, ações e práticas em favor da construção de um mundo menos belicoso, mas não fica claro, de fato, onde isto se encontra em andamento. O caráter ideológico das prescrições vem à tona quando o terceiro mundo é apontado como aquele conjunto de países que não "cuenta con sus propios foros institucionalizados para adelantar una discusión sobre gastos militares" (PNUD, 1991, p. 190), o que leva a entender que tais fóruns existem nos países desenvolvidos. Por essa razão, os produtores do RDH de 1991 passam a aconselhar os países desenvolvidos e em desenvolvimento a perseguirem um conjunto de objetivos em favor da paz mundial.

Obviamente, os que estão incumbidos de produzir o RDH de 1991 não estão supondo que o acordo de paz, de diminuição dos gastos militares e de redução 
da belicosidade pode ser feito fora de um acordo mundial. Todos os países devem estar envolvidos na formulação de uma agenda de ações políticas amplamente negociadas e cooperativas. E para que isto, de fato, funcione, é necessário que nas propostas de desarmamento dos diversos países sejam incluídas "las conversaciones de ayuda. Los países donantes y los países destinatarios [deben discutir] acerca de los gastos militares existentes" (PNUD, 1991, p. 192, grifos do autor).

Consta no RDH de 1991 como é evidente que alguns governos investem muito mais em seus exércitos do que em sua gente (PNUD, 1991, p. 193) e isto indica um baixíssimo compromisso com o desenvolvimento humano. Todavia, seus autores não veem forma de baixar os gastos militares se não houver um pacto, um diálogo entre os países desenvolvidos e os em desenvolvimento. Sem um acordo em torno da diminuição de tais despesas, não seria frutífero imaginar avanços nesta área. Por essa razão, há no RDH de 1991 a seguinte prescrição: toda política de cooperação internacional deve trazer em seu bojo "el tema del alto gasto militar” (PNUD, 1991, p. 193). Os projetos que envolvem cooperação internacional "deben ser una área legítima de diálogo" (PNUD, 1991, p. 193) sobre desarmamento, redução da belicosidade e despesas militares. Para os elaboradores do RDH de 1995, "la escasez de recursos a menudo se presenta como excusa, cuando en realidad se trata de que no se han asignado correctamente las prioridades" (PNUD, 1995, p. 21-22).

\section{DESENVOLVIMENTO E PRIORIDADES HUMANAS: A REDU- ÇÃO DOS GASTOS NÃO ESSENCIAIS}

Não se deve imaginar, de modo algum, que os elaboradores dos $\mathrm{RDH}$ estão supondo que basta diminuir as despesas militares para que sejam alcançadas melhores condições para a expansão do desenvolvimento humano. Não se trata disso, de modo algum. Somente um conjunto de medidas e ações poderá dar resultados satisfatórios. É demonstrado que em muitos países com desempenho muito ruim da economia, com altas taxas de desemprego, de corrupção e de desperdício de dinheiro público, fica impossível insistir somente na necessidade de diminuição dos gastos militares.

Los donantes deberían prepararse para discutir con los gobiernos destinatarios sobre asuntos estructurales fundamentales, tales como la reforma agraria, la distribución del ingreso, los sistemas de crédito, la planificación familiar y los patrones participativos de desarrollo (PNUD, 1991, p. 196). 
Interessa ressaltar que, ao contemplar tais gastos, os produtores e encampadores dos relatórios objetivam assinalar que não é possível desconsiderar os obstáculos que tais gastos põem às políticas que levariam ao desenvolvimento humano. Isto se deve ao fato de que os custos do desenvolvimento são altíssimos e demandam o contingenciamento de todas as despesas públicas. Não se pode ter qualquer ilusão de que bastaria a subtração de alguns milhares de dólares das despesas militares e, em seguida, operar o seu direcionamento às políticas de melhorias sociais para que se garantisse o desenvolvimento humano.

Fazem-se necessários muitos esforços nacionais e internacionais para que haja algum tipo de avanço duradouro e contínuo. Caso contrário, as ações seriam apenas paliativas. No entanto, deve-se ressaltar que, não obstante os relatórios construírem argumentos que façam parecer, como indiscutivelmente necessárias, a ajuda internacional e, portanto, as doações, também elas podem ser paliativas. Mas de que maneira elas são justificadas como imprescindíveis? Pelo fato de que em "nivel internacional, no existe ningún sistema semejante que redistribuya el ingreso eficazmente" (PNUD, 1992, p. 28).

Apresenta-se o relatório de 1991 como defendendo imposições rígidas sobre como deveria ocorrer o gerenciamento dos recursos oriundos da subtração das despesas militares. No documento em análise consta que deveriam ser formuladas exigências claras acerca dos recursos doados pelas organizações internacionais. O grande problema é que, muitas vezes, os doadores têm interesse em remeter ajuda aos países que têm importância estratégico-militar. Neste caso, as ajudas são feitas com o intuito de manter um tipo de controle sobre países e regiões. Os pobres que vivem em regiões consideradas estratégicas militarmente tendem a receber doações muito maiores do que aqueles que vivem em lugares desprovidos de papel militar relevante.

Isto serve, sem nenhuma dúvida, para demonstrar o tamanho do desafio que está posto às apostas dos RDH. Alguns pobres, por viverem em regiões consideradas como militarmente estratégicas, são vistos em razão de tais interesses belicosos. Assim, fica muito difícil, segundo os formuladores dos RDH de 1991 e 1992, construir uma consciência acerca da necessidade de que todos os países (doadores e receptores) deveriam agir em consonância com o desenvolvimento humano e não com os interesses estratégicos militarizados. Este último, até o momento, tem estado em primeiro plano. Se em primeiro lugar estão as estratégias de domínio militares sobre lugares e pessoas, isto evidencia que a redução efetiva e continuada dos gastos militares é, ainda, uma promessa distante. Distante é 
também a promessa de fazer com que os governantes utilizem adequadamente os recursos que recebem de fora como ajuda e cooperação internacionais. Advogando a necessidade de reverter tal situação, os produtores do RDH de 1992 dizem que "los países que reciben más ayuda suelen ser aquellos que no utilizan bien sus recursos: los países con altos gastos militares obtienen aproximadamente el doble de ayuda per cápita que los países de gastos moderados, y más de $25 \%$ más que los países con gastos militares bajos" (PNUD, 1992, p. 29).

Os produtores do RDH de 1992 partem do pressuposto de que houve uma redução dos gastos militares no mundo após o fim da guerra fria e, como se instalou uma política de ajuda e cooperação internacional, teria chegado a hora de envidar esforços na feitura de "un nuevo pacto internacional sobre desarrollo bumano: un acuerdo que coloque a las personas en primer lugar en las políticas nacionales y en la cooperación internacional para el desarrollo" (PNUD, 1992, p. 29). Note-se que, embora tais gastos militares tenham diminuído, "aún siguen siendo equivalentes cada año a los ingresos combinados de la mitad de los habitantes del planeta" (PNUD, 1994, p. 2). Ou seja, "si un gobierno está más preocupado por su plantilla militar que por su población, ese desequilibrio se demuestra en la relación entre gasto militar y gasto social” (PNUD, 1994, p. 37).

Observa-se que os relatórios constroem uma narrativa que aponta para as ingentes dificuldades de reverter algumas condições sociais vigentes na atualidade. A má distribuição de renda, de recursos e de poder também parece, às vezes, de dificílima solução. Por isso, é necessário que haja, segundo consta nos documentos, ajuda e cooperação para melhorar a vida dos mais pobres. Diante da irreversibilidade das desigualdades que potencializam a pobreza cotidianamente, os encampadores dos RDH ajudam a difundir uma ideia que tem se tornado quase um consenso: em vez de questionar a concentração da riqueza, devem-se buscar melhorias para os mais pobres. Este tipo de perspectiva está ancorado na análise de Amartya Sen que advoga a necessidade de "aumentar os recursos disponíveis para a fatia mais pobre da população [...] pelo lado positivo da realização, ou seja, aumentar os recursos para os pobres, não pelo lado negativo, ou seja, diminuindo a riqueza dos ricos"18 (SEN, 2001, p. 11).

Todavia, nota-se algo fundamental ao se analisar os $\mathrm{RDH}$, que são compostos de dois momentos que são, no plano da narrativa ou dos argumentos,

18 É esta uma posição que destoa da de Furtado (1999, 2002). Ele demonstrou que a concentração da renda, expressa nos altos níveis de consumo das classes abastadas, aprofunda as dificuldades de construir investimentos, já que não há uma poupança interna suficiente, que leve à ampliação de melhorias para um número cada vez maior de indivíduos. 
desmembráveis. Há dois planos que devem ser considerados: o dos diagnósticos e o das prescrições. No âmbito do primeiro, há uma radicalidade maior nos argumentos; no do segundo, amenizam-se as constatações mais arrasadoras (a irreversibilidade das desigualdades cada vez mais extremadas) e buscam-se soluções mais amenas. Isso demonstra uma dificuldade imensa de fazer que os diagnósticos e as prescrições sigam uma mesma rota. Conquanto estes dois momentos sejam inteiramente interligados, e formadores de um emaranhado de propostas diversas e ligadas entre si, há, sem dúvida, consequências políticas para esta distância que se estabelece entre diagnósticos e prescrições ${ }^{19}$.

O aumento dos recursos disponíveis para aplicação no desenvolvimento humano passa, conforme os relatórios, por muitos procedimentos (combate à corrupção, melhorias econômicas, aumento da produtividade) públicos e privados. Ao propor outra política orçamentária aos Estados, diminuindo recursos destinados às forças armadas e ampliando os gastos sociais, os RDH têm dado um peso relevante ao Estado ao contar com ele para redefinir o panorama social, ainda que parcialmente, já que as soluções passam sempre, segundo os produtores dos RDH, pela atuação de uma multiplicidade de agentes. Reconhecem-se os direitos sociais ao se prescrever a ampliação dos gastos com saúde, educação, saneamento e moradia.

O enfoque presente nos relatórios não é destituído de uma perspectiva de direitos, mas eles são documentos bastante complexos pelo fato de tal perspectiva de direito vir acompanhada de uma perspectiva das capacidades que pode ser lida equivocadamente ${ }^{20}$, pelos governantes, como uma abordagem meramente cognitiva em que "los grupos excluidos o empobrecidos tienen de mejorar la percepción que tienen de su propria situación” (ETCHICHURY, 2015, p. 58).

Está registrada no RDH de 1994 uma preocupação em torno dos passos que poderiam ser dados para forçar os Estados a reduzir seus gastos militares. Um dos caminhos mais aventado é o da cooperação internacional. Os países beneficiários de ajuda deveriam ter seus gastos controlados e ser obrigados a prestar contas acerca das áreas que estão sendo contempladas com os recursos recebidos de outros países e/ou organizações intergovernamentais. Entende-se que os formuladores deste relatório desejam que se fixem metas de redução e metas de constituição de um

19 Fábio Akira Shishito (2012), que tem trabalhado também com os RDH, foi quem primeiro chamou a atenção para as distâncias entre diagnósticos e prescrições.

20 Equivocadamente porque a abordagem das capacidades de Sen, utilizada parcialmente nos RDH (SEN, 2010, p. 110), pressupõe uma perspectiva de direitos. "Los derechos políticos y civiles ofrecen a las personas la oportunidad de prestar atención a las necesidades generales y demandar una acción política adecuada” (SEN, 2006, p. 66). 
fundo em favor da paz. Deste fundo participariam todos os países que compõem o sistema das Nações Unidas. Ele teria o objetivo de formar um montante de recursos que seriam utilizados para dissuadir formas de belicosidade.

Sugerem os produtores do RDH de 1994 que seja observado, pelos países que participam dos programas de ajuda e cooperação internacional, o modo de aplicação dos recursos oriundos de tais programas. Se os gastos militares forem superiores aos gastos sociais, devem-se examinar com cuidado as políticas de doações, ajudas e empréstimos. Faz-se, então, necessário que os países que dependem de ajuda se disponham a acatar regras para aplicação dos recursos vindos de fora. "Los mismos principios podrían ser incluso más efectivos mediante incentivos positivos, como dar más ayuda a los países que redujeran sus gastos militares" (PNUD, 1994, p. 64).

É importante notar que as regras de contenção dos gastos militares parecem aplicáveis, em razão das condições de dependência de recursos, aos países do eixo sul, os quais deveriam, então, "mudar as suas prioridades orçamentárias" (PNUD, 1994, p. 9). Isto passaria por um investimento maior no ensino primário, no saneamento básico massivo e em melhorias sociais na zona rural. A dependência de ajudas e programas de cooperação aparece como uma condição que abre as portas para que sejam feitas exigências e imposições, acordadas internacionalmente, de redução dos gastos militares aos países pobres e em desenvolvimento. É claro que isto é um ideal a ser alcançado, uma vez que "con frecuencia, la ayuda se ha destinado más a los aliados estratégicos que a los países pobres" 21 (PNUD, 1994, p. 67).

A pergunta é: como sujeitar a um processo de contenção das despesas militares os países ricos e detentores de todas as possibilidades de investimentos em indústrias armamentistas e em logísticas de guerra? Evidentemente, isto parece muito mais complexo no relatório, já que demandaria políticas internacionais de controle a serem formuladas no decorrer das décadas seguintes. Há, no RDH de 1994 (PNUD, 1994, p. 63-64), uma insistência no papel positivo desempenhado pelas Nações Unidas e seu Conselho de Segurança e um apelo para que os dirigentes dos países ricos, com vultosos gastos militares, estejam dispostos a se voltarem para políticas de manutenção da paz.

Ao mencionar os países ricos e extremamente belicosos, os formuladores do RDH de 1994 deixam transparecer o quanto são ainda frágeis os mecanismos

${ }_{21}$ "El Salvador recibió de los Estados Unidos 16 veces más ayuda por habitante pobre que Bangladesh" (PNUD, 1994, p. 84). 
de controle de suas políticas promovedoras de guerras e confrontos ${ }^{22}$. Por isto tateiam de um lado a outro para tentar encontrar um meio de envolver tais nações em um projeto global de construção da paz. Controlar seus gastos militares promotores de todas as formas de belicosidades parece ser algo, no final do século XX e limiar do XXI, inalcançável. Se bem que os responsáveis pela feitura e encampamento dos RDH não assumam, de modo algum, que há dificuldades intransponíveis, estas estão implícitas em várias partes dos documentos. Análises documentais podem revelar coisas que os próprios documentos tentam escamotear. Pressupõe-se, então, que há enunciados latentes que não são perceptíveis "na evidência da linguagem efetiva” (FOUCAULT, 2008, p. 129).

As tentativas de vencer os obstáculos em favor da paz, do desenvolvimento humano, dos direitos humanos e da seguridade humana, levam o RDH de 1994 a defender a aprovação de um "fundo mundial de segurança humana" (PNUD, 1994, p. 10), o qual exigiria a criação de um "Conselho Mundial de Seguridade Econômica" (PNUD, 1994, p. 10) que estivesse voltado para prescrever e acompanhar ações em favor da redução dos gastos militares e, ao mesmo tempo, a expansão dos gastos em desenvolvimento social. Isto seria uma forma de pressionar "los países [que] siguen compitiendo en la miope empresa de la exportación de armas” (PNUD, 1994, p. 10).

\section{CONSIDERAÇÕES FINAIS}

Nos RDH de 1996, 1998 e 1999 há duas prescrições básicas: uma relaciona-se a uma nova forma de gerenciamento dos recursos públicos; a outra diz respeito à necessidade de estipular os setores sociais que deverão ter os seus gastos priorizados. Os formuladores do relatório de 1996 (PNUD, 1996, p. 82 83) trazem críticas aos países do hemisfério norte e do hemisfério sul que tiveram suas despesas militares ampliadas. Eles questionam, por exemplo, o aumento dos gastos militares naqueles países em que os investimentos em saúde e educação são pífios. Eles citam como exemplo os países do norte da África e da Ásia que possuem faixas largas da população em situação de miserabilidade e precariedade extrema de serviços públicos e ainda assim têm gastos militares estratosféricos, se comparados ao que gastam com saúde e educação e ao que destinam para as despesas militares.

22 Isto não quer dizer que não sejam feitas prescrições gerais que atinjam também estes países. "Todos los países deberían convenir en una reducción del 3\% anual de los gastos militares durante el lapso 1995-2005” (PNUD, 1994, p. 7). 
Não se deve imaginar que as críticas aos denominados gastos não essenciais recaem somente sobre os gastos militares. Afinados com os pressupostos do Fundo Monetário Internacional e do Banco Mundial, na década de 1990, os elaboradores do RDH de 1996 insistem que os gastos essenciais são aqueles que atingem a massa empobrecida da população, tais como gastos com infraestrutura (saneamento, por exemplo), com saúde básica e com educação fundamental. Neste caso, eles insistem em criticar os gastos com educação terciária naqueles países em que a população não possui atendimento básico nas diversas áreas (PNUD, 1996, p. 96). Estava em voga, na década de 1990, em várias organizações intergovernamentais, este tipo de entendimento que foi abraçado na feitura do RDH de 1996.

O diagnóstico principal presente nos RDH da década de 1990 é que o mundo enfrentava diversas dificuldades de fortalecer as medidas em favor do desenvolvimento humano (PNUD, 1999). Entre estas dificuldades estavam aquelas que levavam muitos países a investirem muito mais recursos em armas e guerras do que em políticas sociais. O desenvolvimento humano contínuo e duradouro era, como diziam os produtores dos $\mathrm{RDH}$, a única forma de constituir uma nova arquitetura mundial voltada para o combate a muitas ameaças que tornavam a vida das populações mais pobres inteiramente desprotegida e exposta a todos os martírios causados por guerras e conflitos diversos. A diminuição dos gastos militares cumpria, então, dois papéis básicos: um referente à possibilidade de encaminhar tais recursos economizados para os serviços sociais básicos e o outro referente à possibilidade de que a diminuição dos conflitos pudesse levar à ampliação da seguridade humana à medida que as pessoas mais pobres fossem melhorando as condições de vida e de trabalho. Nota-se a insistência de que sociedades voltadas para a perpetuidade de formas belicosas não conseguem fazer grandes avanços rumo ao desenvolvimento humano.

\section{REFERÊNCIAS}

ALMEIDA, C. W. L de. Evolução do orçamento de Defesa no Brasil. In: ALVES DO CARMO, C. et al (Org.). Relações internacionais: olhares cruzados. Brasília: FUNAG, 2013. p. 415- 451.

AZZELLINI, D. América Latina y la privatización de la guerra. Cuaderno de Marte: Revista Latinoamericana de Sociología de la Guerra, Buenos Aires, n. 4, p. $247-$ 262, jul. 2013. Disponível em: http://www.iigg.sociales.uba.ar/revistacuadernodemarte. Acesso em: 24 fev. 2016. 
BALTAZAR, M. da S. O "Estado" das relações civis-militares em democracia. In: CONGRESSO PORTUGUÊS DE SOCIOLOGIA, 4., Coimbra, 2000. Anais [...]. Coimbra: EU, 2000. Disponível em: https://aps.pt/wp-content/uploads/2017/08/ DPR462dbb416b73b_1.pdf. Acesso em: 12 fev. 2016.

BRASIL diminui gastos militares e cai em Ranking. Carta Capital, São Paulo, 15 de abril de 2014. Disponível em: http://www.cartacapital.com.br/politica/br. Acesso em: 08 fev. 2016.

BRUSTOLIN, V. M. Abrindo a caixa preta: o desafio da transparência dos gastos militares no Brasil. 2009. Dissertação (Mestrado em Políticas Públicas, Estratégias e Desenvolvimento) - Instituto de Economia, Universidade Federal do Rio de Janeiro, Rio de Janeiro, 2009. Disponível em: http://www.ie.ufrj.br/images/pós-garduacao/pped/ defesa. Acesso em: 20 fev.2016.

CARILHO, M. Principais tendências na sociologia militar. Lisboa: Universidade de Lisboa, 1978. p 156-169. Disponível em https://core.ac.uk/download/pdf/62688595. pdf. Acesso em: 16 fev. 2016.

CASTRO, J. de. Geopolítica da fome: ensaio sobre os problemas de alimentação e de população no mundo. São Paulo: Brasiliense, 1961. v. 1 e 2.

CASTRO, J. de. Geografia da fome. Rio de Janeiro: Civilização Brasileira, 2001.

CUSTERS, P. Economias verdes e crescimento zero. Le Monde Diplomatique Brasil. 05 maio de 2009, Mundo. p. 1-4. Disponível em: https:/ / diplomatique.org.br/economiasverdes-e-crescimento-zero/. Acesso em: 10 fev. 2016.

DEGER, S.; SEN, S. Military expenditure and developing countries. In: HARTLEY, K.; SANDLER, T. (Eds.). Handbook of Defense Economics. Amsterdam: Elsevier Science, 1995. p. 275-307.

DIKICI, E. Guns versus Butter Tradeoff: the theory of defense - Quality factor. Journal of Economics, Business and Management, Singapura, v. 3, n.7, p. 1-6, jul. 2015. Disponível em: http://www.joebm.com/papers/270-X00007.pdf. Acesso em 01 ago. 2019.

DRAPER, W. Foreword. In: PNUD. Relatório do Desenvolvimento Humano (RDH) 1991: financiamento do desenvolvimento humano. New York: PNUD/ONU, 1991. p. III-IV. Disponível em: http://hdr.undp.org/en/reports/global/hdr1991. Acesso em: 02 fev. 2016.

ELIAS, N. A condição humana: considerações sobre a evolução da humanidade por ocasião do quadragésimo aniversário do fim de uma guerra. Rio de Janeiro: Bertrand Brasil, 1991.

ELIAS, N. A sociedade dos indivíduos. Rio de Janeiro: Jorge Zahar Editores, 1994a.

ELIAS, N. Teoria simbólica. Oeiras: Celta Editora, 1994b.

ELIAS, N. Envolvimento e alienação. Rio de Janeiro: Bertrand Brasil, 1998.

ELIAS, N. Norbert Elias por ele mesmo. Rio de Janeiro: Jorge Zahar, 2001. 
ETCHICHURY, H. J. La mente, la pobreza y el banco mundial: una perspectiva de derechos humanos. Revista Enfoques, Santiago, n. 23, p. 49-65, 2015.

FERNANDES, F. B. As relações civil-militares durante o governo Fernando Henrique Cardoso - 1995/2002. 2006. 156f. Dissertação (Mestrado em Ciência Política) - Programa de Pós-Graduação em Ciência Política, Universidade de Brasília, Brasília, 2006. Disponível em: http://repositorio.unb.br/bitstream/10482/2415/1/Fernando\%20 B\%20Fern.pdf. Acesso em 23 fev. 2016.

FOUCAULT, M. A arqueologia do saber. Rio de Janeiro: Forense-Universitária, 2008.

FURTADO, C. A reconstrução do Brasil. Praga: estudos marxistas, São Paulo, n. 8, p. 9-13, ago. 1999.

FURTADO, C. Em busca de novo modelo. Rio de Janeiro: Paz e Terra, 2002.

HARTLEY, K.; SANDLER, T. (Ed.). Handbook of defense Economics. Amsterdam: Elsevier Science, 1995. v. 1.

HARTLEY, K.; SANDLER, T. (Ed.). Handbook of defense Economics. Amsterdam: Elsevier Science, 2007. v. 2.

HERRERA, R. O renascimento neoliberal da economia do desenvolvimento. O Diario. Info. Santiago de Compostela, 06 nov. 2006. Caderno Atualidade, p. 1. Disponível em: www.galizacig.gal/actualidade/200611/odiario. Acesso em: 05 jul. 2016.

MALIK, K. Agradecimentos. In: PNUD. Relatório do Desenvolvimento Humano (RDH) 2013: a ascensão do Sul: progresso humano num mundo diversificado. New York: PNUD/ONU, 2013. p. VI-VII. Disponível em: https://www.undp.org/content/ dam/brazil/docs/RelatoriosDesenvolvimento/undp-br-hdr_portuguese-2013.pdf. Acesso em: 20 mar. 2018.

MILLS, W. A ascendência militar. In: MILLS, W. A elite do poder. Rio de Janeiro: Zahar, 1981. p. 237-288.

PEREIRA, A. Não dá para engolir tudo. Folha de S. Paulo, São Paulo, 16 nov. 2015. Caderno A, p. 3. Disponível em: www1.folha.uol.com.br/opiniao/2015/11/1706297-naoda-para-engolir-tudo.shtml. Acesso em: 03 mar.2018

PNUD. Relatório do Desenvolvimento Humano (RDH) 1991: financiamento do desenvolvimento humano. New York: PNUD/ONU, 1991. Disponível em: http://hdr. undp.org/en/reports/global/hdr1991. Acesso em: 02 fev. 2018.

PNUD. Relatório do Desenvolvimento Humano (RDH) 1992: dimensões globais do desenvolvimento humano. New York: PNUD/ONU, 1992. Disponível em: http://hdr. undp.org/en/reports/global/hdr1992. Acesso em: 03 mar. 2018.

PNUD. Relatório do Desenvolvimento Humano (RDH) 1994: novas dimensões da segurança humana. New York: PNUD/ONU, 1994. Disponível em: Disponível em: http://hdr.undp.org/en/reports/global/hdr1994. Acesso em: 20 jan. 2018. 
PNUD. Relatório do Desenvolvimento Humano (RDH) 1995: gênero e desenvolvimento humano. New York: PNUD/ONU, 1995. Disponível em: http://hdr. undp.org/en/reports/global/hdr1995. Acesso em: 12 jan. 2018.

PNUD. Relatório do Desenvolvimento Humano (RDH) 1996: crescimento econômico e desenvolvimento humano. New York: PNUD/ONU, 1996. Disponível em: http://hdr. undp.org/en/reports/global/hdr1996. Acesso em: 03 fev. 2018.

PNUD. Relatório do Desenvolvimento Humano (RDH) 1997: desenvolvimento humano para erradicar a pobreza. New York: PNUD/ONU, 1997. Disponível em: http://hdr.und:org/en/reports/global/hdr1997. Acesso em: 02 fev. 2018.

PNUD. Relatório do Desenvolvimento Humano (RDH) 1998: cambiar as pautas actuales de consumo para el desarrollo humano del futuro. New York: PNUD/ONU, 1998. Disponível em: http://hdr.undp.org/en/reports/global/hdr1998. Acesso em: 21 fev. 2018.

PNUD. Relatório do Desenvolvimento Humano (RDH) 1999: la mundialización com rostro humano. New York: PNUD/ONU, 1999. Disponível em: http://hdr.undp. org/en/reports/global/hdr1999. Acesso em: 12 fev. 2018.

PNUD. Relatório do Desenvolvimento Humano (RDH) 2002: aprofundar a democracia num mundo fragmentado. New York: PNUD/ONU, 2002. Disponível em: $\quad$ http://www.br.undp.org/content/brazil/pt/home/library/idh/relatorios-dedesenvolvimento-humano/relatorio-do-desenvolvimento-humano-20002.html Acesso em: 31 jul. 2019.

PNUD. Relatório do Desenvolvimento Humano (RDH) 2005: cooperação internacional numa encruzilhada: ajuda, comércio e segurança num mundo desigual. New York: PNUD/ONU, 2005. Disponível em: http://www.br.undp.org/content/brazil/pt/home/ library/idh/relatorios-de-desenvolvimento-humano/relatorio-do-desenvolvimentohumano-20005.html Acesso em 01 ago. 2019.

PNUD. Relatório do Desenvolvimento Humano (RDH) 2011: sustentabilidade e equidade: um futuro melhor para todos. New York: PNUD/ONU, 2011. Disponível em: http://hdr.undp.org/en/content/human-development-report-2011. Acesso em: 01 ago 2019 .

PNUD. Relatório do Desenvolvimento Humano (RDH) 2013: a ascensão do Sul: progresso humano num mundo diversificado. New York: PNUD/ONU, 2013. Disponível em: http://www.br.undp.org/content/brazil/pt/home/library/idh/relatorios-dedesenvolvimento-humano/relatorio-do-desenvolvimento-humano-200012.html Acesso em: 31 maio 2018.

RELATÓRIO ANUAL DA COMISSÃO ECHO, 2003. Comissão das Comunidades Europeias para Ajuda Humanitária. Bruxelas, Bélgica. Disponível em: https://eur-lex. europa.eu/LexUriServ/LexUriServ.do?uri=CELEX:52004DC0583:PT:HTML. Acesso em: 01 ago. 2019. 
SCHAUBLE, W. apud Schauble pronto para aumentar as despesas militares alemãs. Jornal de Negócio, Lisboa, 27 dez. 2015. Caderno de Economia, p. 1. Disponível em: http:// www.jornaldenegocios.pt/economia. Acesso em: 18 fev. 2016.

SEN, A. Poverty and Famines: An Essay on Entitlement and Deprivation. Oxford: CLARENDON PRESS, 1981

SEN, A. Resources, Values and Development, Oxford: Basil Blackwell, 1984.

SEN, A. Sobre ética e economia. São Paulo: Cia das Letras, 1999.

SEN, A. Entrevista programa Roda Vida da TV Cultura. 2001. Memória Roda Vida. Disponível em: http://www.rodaviva.fapesp.br. Acesso em: 02 jan. 2012.

SEN, A. E1 valor de la democracia. Madrid: El Viejo Topo, 2006.

SEN, A. Desigualdade reexaminada. Rio de Janeiro: Record, 2008.

SEN, A. Desenvolvimento como liberdade. São Paulo: Cia das Letras, 2010.

SEN, A. A ideia de justiça. São Paulo: Cia das Letras, 2011.

SHISHITO, F. A. Os Relatórios do Desenvolvimento Humano das Nações Unidas: entraves e desafios que emergem da periferia. Londrina. 2012. Dissertação (Mestrado em Ciências Sociais) - Programa de Pós-Graduação em Ciências Sociais, Universidade Estadual de Londrina, Londrina, 2012.

SILVA FILHO, E. S.; MORAES, R. F. de. Dos “Dividendos da Paz”: a guerra contra o terror, gastos militares mundiais nas duas décadas após o fim da guerra fria - 1991-2009. Rio de Janeiro, IPEA, 2012. (Texto para Discussão, 1754).

SIPRI YEARBOOK. Military Expenditure. 2015. Disponível em: HTTPS,//www. sipri.org/yearbook/2015/09. Acesso em: 13 jan. 2018.

SWEEZY, P. Comments on Szymanski's paper "Military spending and economic stagnation”. American Journal of Sociology, New York, n. 79, p. 109-110, nov. 1973.

SWEEZY, P.; BARAN, P. Monopoly capital - an essay on the American economic and social order. New York: Monthly Rewiew Press, 1966.

SZYMANSKI, A. Military spending and economic stagnation. American Journal of Sociology, New York, n. 79, p. 1-14, jul. 1973.

UL HAQ, M. The Strategy of Economic Planning. Oxford: Oxford University Press, 1963.

UL HAQ, M. A cortina da pobreza: opções para o terceiro mundo. São Paulo: Nacional, 1978.

UL HAQ, M. Reflections on Human Development. Nova York: Oxford University Press, 1995. 288p.

Texto submetido à Revista em 02.07.2018

Aceito para publicação em 22.05.2019 
